\title{
Help received from relatives and services to satisfy needs of adults with severe mental disorders
}

\author{
Marie-Josée Fleury ${ }^{1^{\star}}$, Guy Grenier ${ }^{2}$, Jean-Marie Bamvita ${ }^{2}$ \\ ${ }^{1}$ Department of Psychiatry, McGill University Douglas Hospital Research Centre, Montreal, Canada; \\ *Corresponding Author: flemar@douglas.mcgill.ca \\ ${ }^{2}$ Douglas Hospital Research Centre, Montreal, Canada
}

Received 7 December 2012; revised 5 January 2013; accepted 12 January 2013

\begin{abstract}
Background: Few studies have considered the impact of demographic and clinical variables on help received respectively from services and relatives to satisfy needs of adults with severe mental disorders (SMD). Purposes: To identify major needs receiving help and, using the Andersen's Behavioural Model of Health Service Use, to identify and compare predisposing, enabling and need factors associated with help given respectively by services and relatives. Methods: 352 adults with SMD from Montreal (Canada) were interviewed using six standardized instruments. Clinical records were consulted. Multiple linear regression analyses were processed to measure level of help received from relatives and services. Results: Factors significantly associated with help from relatives were: higher number of perceived needs; fewer diagnoses; better community functioning; being younger, and in a conjugal relationship; living autonomously; having social support and better quality of life; and, marginally, being an immigrant. Factors significantly associated with help from services were: higher number of perceived needs, better quality of life, supervised housing, adjustment disorder and schizophrenia. Conclusions: Help overall is insufficient to meet users' needs. Services are more helpful than relatives, in particular regarding health needs. Comparatively to help from services, help from relatives is associated with predisposing factors like age, marital status and nationality.
\end{abstract}

Keywords: Help from Relatives; Help from Services; Needs Assessment; Severe Mental Disorders;

Service Utilisation

\section{INTRODUCTION}

As a result of deinstitutionalization and greater focus on treatment in the community, individuals with severe mental disorders (SMD) have been increasingly living with their family or regularly keeping in touch with them [1]. The proportion of individuals with SMD in the United States who have regular contacts with their family is between $50 \%$ and $90 \%$ [2]. Between $40 \%$ and $50 \%$ of individuals with schizophrenia in Canada live with their family [3]. Consequently, relatives are called upon to supply help - mostly related to daily activities - that was formerly provided by psychiatric institutions [4].

While several studies discuss mental health service utilisation, few compare use of professional services and support from family and friends (informal supports) [5-9]. According to these studies, informal supports cannot serve as a substitute for professional services and are most effective in an adjunct role. However, such studies do not usually draw a link between professional services or informal supports and users' perceived needs.

Needs assessment is a key issue as it relates to both service planning and treatment [10]. From an epidemiological perspective, needs assessments facilitate the planning, provision and evaluation of mental health services required to adequately serve a population within a specific territory [11]. For case managers and caregivers, needs assessments complete the clinical evaluation and are useful to plan discharge from hospital and draft an adequate intervention care plan $[4,10,12]$. Ideally, intervention should be tailored to the user's needs [13]. Those needs can be met by health and social services (formal help) or relatives (informal help).

While several studies have focussed on needs assessments for adults with SMD, few of them have investigated help provided respectively by services and relatives [4,10,12,14-19]. Those studies have shown that users usually received more help from services than from relatives $[14,16]$. However, help from relatives is more prominent in the weeks following a suicide attempt [10] or a discharge from a psychiatric hospital [12]. Formal and informal help are, in fact, complementary: users generally received help from both services and relatives for the majority of their needs [17]. 
Furthermore, few studies have considered the impact of demographic and clinical variables on help received respectively from services and relatives to satisfy needs $[17,18]$. The most frequently used tool for identifying factors associated with service use is Andersen's Behavioural Model of Health Service Use [20]. This model classifies predictors of service use into three categories: 1) predisposing, 2) enabling, and 3 ) needs factors. Predisposing factors are individual characteristics that exist prior to the illness such as age and gender. Enabling factors are features that influence care delivery and encompass variables such as income and social support. Finally, needs factors include assessments of physical and mental health by patients and professionals, including diagnosis and perceived needs. Using the behavioural model to determine factors predictive of formal and informal help for needs of older adults with SMD according the Camberwell Assessment of Needs for the Elderly (CANE), Cummings \& Kropf [18] found three factors predicting help from services (type of residence, daily activities and dangerous behaviour needs areas) and four predicting help from relatives (type of residence, and looking after the home, money and self-care needs areas). To our knowledge, however, the behavioural model has never been used to identify factors associated with help received to satisfy the needs of adults with SMD.

\section{AIMS}

This article has a dual aim: 1) to identify which needs of adults with SMD are mostly being met by services and relatives; and 2) to identify and compare predisposing, enabling and needs factors associated with help given by services and relatives.

\section{METHOD}

\subsection{Study Design and Network Characteristics}

This study had a cross-sectional design. The study population involved adults with SMD who were monitored by a mental health institute (MHI) located in the south-western part of the city of Montreal (Quebec, Canada). This urban area, encompassing a population of 258,000 , is served by two local health networks. The MHI offers specialised mental healthcare care (i.e. second- and third-line services).Two health and social service centres (HSSCs), created through the merger of a general hospital, community local service centres, andnursing homes, provide mainly first-line mental healthcare services. Sixteen community-based agencies delivering mental health services are also present (e.g. crisis centre, day-care centres, self-help groups, back-to-work programs). General practitioners and psychologists practicing in private clinics, and institutional mental health housing (e.g. intermediate residence, foster home) complete the mental health network in this area.

\subsection{Sample Selection Criteria and Recruitment of the Main Sample}

To participate in the study, participants had to be aged between 18 to 65 years old, and diagnosed with SMD according to the DSM-IV (e.g. schizophrenia, bipolar disorder). In addition, they had to live in the community within the two HSSCs areas, have a stable mental health condition, and be available for a follow-up assessment by the mental health institute. Finally, the participants had to give their consent to the research team consulting their medical record, and they also had to refer the research team to their principal case manager who would be asked thereafter to fill a questionnaire on their functional condition. Individuals with severe mental retardation, following involuntary psychiatric treatment as determined by a judiciary board, or with a history of hospitalization or emergency room visits in the three months prior to the initial interview were considered unable to complete the questionnaires and were thus excluded from the study. Data collection ran from December 2008 to September 2010. Recruitment involved various strategies: posters at the mental health institute (MHI) and HSSCs for participant self-referral; recruitment at the MHI out-patient clinics, and information sessions or letters sent to explain the project to providers or the housing resource network. The research team worked closely with an advisory committee of decision makers from the mental health network to assist in data collection.

Interviews were conducted by a team of well-trained clinical professionals, constantly in touch with a research coordinator. Except for self-referral, participants selected were contacted by their case manager, who gauged their interest in participating in the study, and subsequently referred participants to the research team. Two 90-minute interviews, at one week interval, were conducted with each patient. Each participant was required to sign a consent form after the study was described to them. The study protocol had been approved by the ethics boards of the MHI and the two HSSC.

\subsection{Measurement Instruments}

Data was collected using six questionnaires, administered both in English and French, and from participants' medical records at the MHI. 1) The Montreal Assessments of Needs Questionnaire (MANQ) is derived from the Camberwell Assessment of Need (CAN), which is the most reliable and frequently used instruments for needs assessment [21]. The CAN assesses participant needs in 22 areas, divided into five categories: a) basic needs (accommodations, food and day-time activities); 
b) health (physical health, psychotic symptoms, psychological distress, safety to self, safety to others, alcohol use, and drug use); c) functioning (self-care, looking after the home, child care, basic education, and money); d) social (company, intimate relationships, and sexual expression); and e) services (information about illness and treatment, transportation, telephone, and benefits). The CAN evaluates needs by taking into account their number and intensity (no need, met need, unmet need), along with the level of help received from relatives and services (no help, low help, moderate help, high help), the level of help that users need from local services (no help, low help, moderate help, high help) and the adequacy of help in regards to needs expressed, in term of quality and quantity (yes, no). Within the MANQ, four areas were added, for a total of 26: job integration, stress adaptation, social exclusion, and involvement in treatment decisions. For individuals with SMD, job integration is an important issue since it is difficult for most of them to find work due to individual characteristics or environmental barriers [22]. The literature also mentions that social exclusion and stigmatization is often more difficult to cope with than the SMD itself $[23,24]$. Furthermore, vulnerability to stress is associated with a greater severity of psychotic symptoms [25]. Finally, involvement in treatment decisions constitutes an important dimension of recovery [26]. Contrary to the original CAN, in which participants' needs are measured based on ordinal scale questions, the MANQ used analogical scales, ranging from 0 to 10 . The purpose of this change was to enhance variability in the data without compromising precision. Other standardized instruments used were as follows: 2) Alcohol Use Disorders Identification Test (AUDIT), measuring the degree of dependency and riskyalcoholconsumption (Cronbach alpha-CA: 0.88; [27]); 3) Drug Abuse Screening Test (DAST), evaluating drug abuse and its consequences (CA: 0.74; [28]); 4) Social Provisions Scale (SPS), exploring participants' level of integration and social support (CA: 0.92; [29]); 5) Satisfaction with Life Domains Scale (SLDS), assessing quality of life (CA: 0.92; [30]); and 6) Multnomah Community Ability Scale (MCAS), assessing patients' functional status in the community (CA: 0.87; [31]). All questionnaires were completed by the participants, except the MCAS, which was completed by the participant's principal case manager. Participants' medical records were used to compile complementary clinical data: DSM-IV diagnoses, number of prior suicide attempts, and history of prior violence.

\subsection{Analyses}

The MANQ has been validated using many analyses (factor analyses, Chronbach Alpha, inter-rater, test-retest reliability), concordance with other instruments (such as MCAS and SLDS), and corresponding values on the MANQ for each category of the CAN [32]. Participants were asked to complete the MANQ and CAN during the same interview. Overall, validation analyses showed comparable results between the two instruments. Chronbach Alpha in the MANQ ranged from 0.70 to 0.73 (versus 0.68 to 0.71 for the CAN). The mean values for CAN and MANQ for each needs domain were correlated with global scores from MCAS and SLDS, forming a consistent correlation pattern for both. The kappa coefficients ranged from 0.46 to 1.00 for the test-retest reliability and from 0.64 to 1.00 for the inter-rater reliability.

The analyses frame was built into the conceptual model displayed in Figure 1. Two continuous dependent variables were built: "level of help received from relatives", and "level of help received from services". Each dependent variable was given a score calculated by adding, for each participant, the scores illustrating the level of help received for each perceived need (from relatives for the former, and from services for the latter). The independent variables, as shown in Figure 1, are organised in three categories: predisposing factors, enabling factors, and need factors, respecting Andersen's behavioural model.

Normality assumptions were verified before going through analyses. No transformation was needed. Analyses encompassed descriptive analyses, bivariate analyses and hierarchical linear regression analyses. The purpose of bivariate analyses was to select independent variables associated with the dependent variables, for an alpha value set at $\mathrm{P}<0.10$. Independent variables yielding a significant association were used to build the hierarchical linear regression models, setting the alpha value at $\mathrm{P}<$ 0.05 . The total variance explanation and the goodness of fit were generated.

\section{RESULTS}

Overall, 437 participants were approached. From the housing mental health network, $116(27 \%)$ lived in an intermediate resource (i.e. a housing resource linked by contract to a public institution), $61(14 \%)$ in a foster home, and $254(58 \%)$ in other types of housing (e.g. autonomous or supervised housing). Participants mean age differed by housing types (respectively: 51 [SD: 19.5], 49 [SD: 11.5] and 45 [SD: 10.6] years old). A total of 352 potential subjects $(81 \%)$ agreed to participate, while 86 declined (20\%). Refusals were compared to participants as to gender and housing type. No statistically significant difference was found regarding 1) intermediate residence participants (Khi-square: $5.999[\mathrm{P}=$ $0.199]$ ); 2) foster home participants (Khi-square: 4.482 


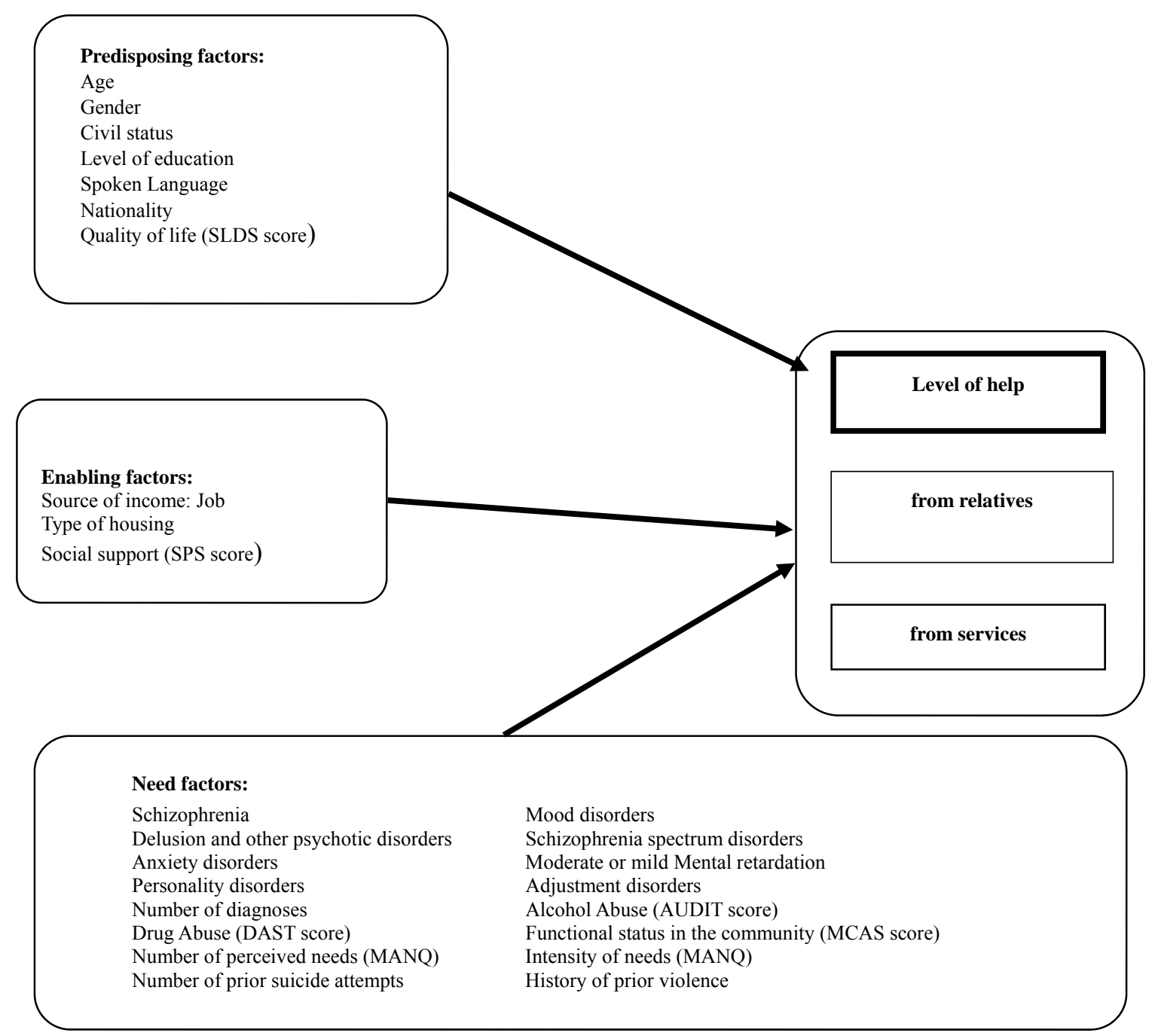

Figure 1. Conceptual framework factors associated with help from relatives and services to satisfy needs among adults with severe mental disorders.

$[\mathrm{P}=0.482]) ; 3$ ) or other housing type (Khi-square: 3.229 $[\mathrm{P}=0.665])$. Participants and refusals were also compared as to gender distribution (total sample); again, no statistically significant difference was found: Khi-square: $1210 ; \mathrm{P}=0.271$.

Socio-demographic, socio-economic and clinical characteristics of the 352 participants are displayed in Table 1. The mean age for the 352 participants was 46.5 (SD: 10.9), with 186 males (53\%) and 166 females (47\%). Most of the participants were natives of Canada (92\%) and French-speaking (64\%). Only 13\% were married or in a conjugal relationship. Sixty-six per cent were on social welfare. The majority did not have a post-secondary diploma (65\%). Sixty per cent lived in an autonomous apartment. Considering cut-offs at 8 and 6 for the AUDIT and the DAST scores respectively [33], 143 individuals $(41 \%)$ versus $53(15 \%)$ in the sample could be considered as addicted to alcohol versus addicted to drugs. The most prevalent severe mental health disorders were mood disorders $(41 \%)$ and schizophrenia (38\%). Presence of comorbidity was noted for $48 \%$ of participants, the most prevalent mental health disorder as second diagnosis was personality disorders $(28 \%)$.

Detailed description of perceived needs and help received for those needs are displayed in Table 2. The first two results columns report the number of participants having a specific need. The five most reported needs are: psychological distress (70\%), stress adaptation (63\%), physical health (56\%), psychotic symptoms $(48 \%)$, and money (47\%). The relative importance attributed to perceived needs is shown in the second column. As regards intensity of perceived needs, the highest means relate to childcare (mean: 7.5), job integration (mean: 7.5), drugs (mean: 7.4), sexual expression (mean: 7.4), intimate relationships (7.3), and benefits (mean: 7.3). The third and fourth columns display results related to the level of 
Table 1. Socio-demographic, socio-economic and clinical variables $(\mathrm{N}=352)$.




Table 2. Descriptive analyses of needs and help received $(\mathrm{N}=352)$.

\begin{tabular}{|c|c|c|c|c|c|c|c|}
\hline \multirow{3}{*}{ Categories of needs } & \multirow{2}{*}{$\begin{array}{c}\text { Participants } \\
\text { with specific } \\
\text { needs }\end{array}$} & \multirow{2}{*}{$\begin{array}{c}\begin{array}{c}\text { Intensity of } \\
\text { needs }\end{array} \\
\text { [Mean (SD)] }\end{array}$} & \multirow{2}{*}{$\begin{array}{c}\text { Level of help } \\
\text { received from } \\
\text { relatives }\end{array}$} & \multirow{2}{*}{$\begin{array}{c}\text { Level of help } \\
\text { received from } \\
\text { service } \\
\text { providers }\end{array}$} & \multicolumn{3}{|c|}{$\begin{array}{l}\text { Comparison of the ratio of participants receiving } \\
\text { help from relatives versus from service providers }\end{array}$} \\
\hline & & & & & $\begin{array}{c}\text { Participants } \\
\text { receiving help } \\
\text { from relatives } \\
\text { for each specific } \\
\text { need }\end{array}$ & $\begin{array}{l}\text { Participants } \\
\text { receiving help } \\
\text { from service } \\
\text { providers for } \\
\text { each specific } \\
\text { need }\end{array}$ & $P$ value \\
\hline & & & & & {$[(\mathrm{n}(\%)]$} & {$[(\mathrm{n}(\%)]$} & (Chi square) \\
\hline Accommodation & $123(34.9)$ & $5.9(3.0)$ & $1.6(3.0)$ & $3.2(4.2)$ & $31(25.2)$ & $52(42.3)$ & 0.642 \\
\hline Food & $118(33.5)$ & $5.3(2.4)$ & $3.3(3.9)$ & $3.4(4.0)$ & $61(51.7)$ & $60(50.8)$ & 0.139 \\
\hline Looking after the home & $116(33.0)$ & $5.8(2.5)$ & $2.4(3.6)$ & $1.7(3.4)$ & $46(39.7)$ & $27(23.3)$ & 0.003 \\
\hline Self-care & $60(17.0)$ & $5.3(2.8)$ & $1.5(3.0)$ & $3.2(4.2)$ & $16(26.7)$ & $27(45.0)$ & 0.014 \\
\hline Day-time activities & $121(34.4)$ & $5.5(2.7)$ & $1.9(2.9)$ & $3.3(3.9)$ & $46(38.0)$ & $61(50.4)$ & 0.762 \\
\hline Physical health & $198(56.3)$ & $5.8(2.8)$ & $1.5(3.1)$ & $4.8(3.7)$ & $45(22.7)$ & $151(76.3)$ & 0.285 \\
\hline Psychotic symptoms & $169(48.0)$ & $5.6(2.8)$ & $2.2(3.6)$ & $7.3(3.3)$ & $53(31.4)$ & $153(90.5)$ & 0.023 \\
\hline Information & $80(22.7)$ & $6.0(2.8)$ & $0.9(2.6)$ & $2.3(3.1)$ & $14(17.5)$ & $37(46.3)$ & 0.037 \\
\hline Psychological distress & $245(69.6)$ & $6.6(2.7)$ & $4.1(4.2)$ & $5.3(3.9)$ & $134(54.7)$ & $177(72.2)$ & 0.003 \\
\hline Safety to self & $69(19.6)$ & $5.9(2.8)$ & $3.0(4.1)$ & $4.3(4.1)$ & $28(40.6)$ & $42(60.9)$ & 0.047 \\
\hline Safety to others & $28(8.0)$ & $5.5(3.0)$ & $3.3(4.6)$ & $3.8(3.9)$ & $11(39.3)$ & $16(57.1)$ & 0.823 \\
\hline Alcohol & $36(10.2)$ & $5.1(2.4)$ & $1.6(3.2)$ & $2.0(3.2)$ & $9(25.0)$ & $12(33.3)$ & 0.414 \\
\hline Drugs & $131(37.2)$ & $7.4(3.0)$ & $1.4(3.1)$ & $6.4(4.2)$ & $25(19.1)$ & $98(74.8)$ & 0.166 \\
\hline Company & $123(34.9)$ & $6.5(2.7)$ & $1.9(3.1)$ & $1.5(2.8)$ & $31(25.2)$ & $52(42.3)$ & 0.011 \\
\hline Intimate relationships & $144(40.9)$ & $7.3(2.8)$ & $1.6(2.9)$ & $1.4(2.9)$ & $44(30.6)$ & $35(24.3)$ & 0.008 \\
\hline Sexual expression & $110(31.3)$ & $7.4(2.8)$ & $1.7(3.2)$ & $1.4(2.7)$ & $32(29.1)$ & $33(30.0)$ & 0.003 \\
\hline Childcare & $23(6.5)$ & $7.5(2.9)$ & $5.0(4.4)$ & $3.0(3.9)$ & $15(65.2)$ & $10(43.5)$ & 0.645 \\
\hline Basic education & $51(14.5)$ & $5.9(3.0)$ & $1.9(3.5)$ & $1.9(3.6)$ & $16(31.4)$ & $14(27.5)$ & 0.346 \\
\hline Telephone & $12(3.4)$ & $6.6(2.8)$ & $2.5(4.5)$ & $1.7(1.9)$ & $3(25.0)$ & $6(50.0)$ & 0.505 \\
\hline Transportation & $83(23.6)$ & $6.9(3.0)$ & $2.7(4.0)$ & $2.7(4.0)$ & $30(36.1)$ & $33(39.8)$ & 0.368 \\
\hline Money & $167(47.4)$ & $6.9(2.9)$ & $2.5(3.8)$ & $3.8(4.3)$ & $59(35.3)$ & $82(49.1)$ & $<0.001$ \\
\hline Benefits & $40(11.4)$ & $7.3(3.0)$ & $1.0(2.7)$ & $2.0(3.4)$ & $10(25.0)$ & $14(35.0)$ & 0.251 \\
\hline Job integration & $125(35.5)$ & $7.5(2.5)$ & $0.6(2.0)$ & $2.5(3.7)$ & $13(10.4)$ & $49(39.2)$ & 0.019 \\
\hline Stress adaptation & $221(62.8)$ & $6.3(2.6)$ & $4.0(4.0)$ & $4.5(3.9)$ & $130(58.4)$ & $145(65.6)$ & 0.436 \\
\hline Social exclusion & $110(31.3)$ & $6.5(2.9)$ & $2.4(3.7)$ & $2.6(3.7)$ & $41(37.3)$ & $44(40.0)$ & $<0.001$ \\
\hline Involvement in treatment decisions & $71(20.2)$ & $6.5(3.0)$ & $1.8(3.5)$ & $2.7(3.1)$ & $17(23.9)$ & $38(53.5)$ & 0.106 \\
\hline TOTAL SAMPLE & $107(30.3)$ & $6.6(2.8)$ & $2.3(2.4)$ & $3.9(2.5)$ & $37(32.9)$ & $56.5(48.6)$ & 0.021 \\
\hline
\end{tabular}

help received from relatives and services respectively, for each specific need reported. Perceived needs for which participants received help mostly from relatives are childcare, psychological distress, stress adaptation, food and safety to others. At the same time, help from services was mostly related to psychotic symptoms, drugs, psychological distress, physical health and stress adaptation. The level of help received from relatives is higher than the level of help received from services in five areas (childcare, telephone, looking after the home, sexual expression, and intimate relationships) and equal in two others (transportation, basic education). In healthrelated areas (psychotic symptoms, physical health, drugs, psychological distress, safety to self, safety to others, and alcohol), the level of help received from services is notably higher than the level of help received from relatives. A majority of participants did not receive help appropriate to their level of need, and a critical number of these individuals received no help from services or their informal network for one or more of their needs. 
The fifth and sixth columns (again in Table 2) indicate the ratio of participants who received help from relatives and services respectively. For each perceived need, a comparison was also made between these ratios in the seventh column. As illustrated by $\mathrm{P}$ values, the ratio of participants receiving help from relatives is higher than that of participants receiving help from services in only two areas: looking after the home and intimate relationships. In the following ten areas, significantly more participants received help from services than from relatives: self-care, psychotic symptoms, information, psychological distress, safety to self, company, sexual expression, money, job integration, and social exclusion.

The hierarchical linear regression model assessing help from relatives is displayed in Table 3. From the block of predisposing factors, four variables were retained: being younger, being in a conjugal relationship, quality of life according the SLDS score and, marginally, being of a nationality other than Canadian. From the block of enabling factors, to live in autonomous housing and social support according the SPS score were retained in the model, both being positively associated with the dependent variable. From the third block of need factors, three variables were retained in the final model: number of diagnoses (negatively associated), functional skills in the community according the MCAS score and number of perceived needs (both positively associated).

The goodness-of-fit for this model is acceptable, with $31 \%$ of total variance explained. From the block of pre- disposing factors, one variable was retained: quality of life according the SLDS score, which was positively associated. From the block of enabling factors, one variable was retained: type of housing, which shows that people living in autonomous housing received less help from services. From the third block of need factors, three variables were retained in the final model: schizophrenia, adjustment disorders and number of perceived needs, the three variables being positively associated with help from services. The goodness-of-fit for this model is acceptable, with $39 \%$ of total variance explained. The hierarchical linear regression model assessing help from services is displayed in Table 4.

\section{DISCUSSION}

The purposes of this article were to identify needs receiving help from relatives and services respectively and to identify and compare predisposing, enabling and need factors, associated respectively with help given by services and relatives to meet the needs of adults with SMD. Participants were interviewed using six instruments, and clinical records were consulted.

Overall, participants' cohort distribution with respect to socio-demographic profiles and clinical characteristics was comparable to that of most of previous studies concerning needs assessments for adults with SMD [15, 34-36]. The main difference was the lower proportion of schizophrenic cases in our sample, which could explain

Table 3. Variables independently associated with level of help received from relatives among patients with severe mental disorders: multiple linear regression analysis $(\mathrm{N}=352)$.

\begin{tabular}{|c|c|c|c|c|c|c|c|c|c|}
\hline & & \multicolumn{2}{|c|}{ Predisposing factors } & \multicolumn{2}{|c|}{ Enabling factors } & \multicolumn{4}{|c|}{ Need factors } \\
\hline & & \multirow{2}{*}{$\beta$} & \multirow{2}{*}{$\mathbf{P}$} & \multirow{2}{*}{$\beta$} & \multirow{2}{*}{$\mathbf{P}$} & \multirow{2}{*}{ Standardized $\beta$} & \multirow{2}{*}{$\mathbf{t}$} & \multirow{2}{*}{$\mathbf{P}$} & \multirow{2}{*}{$\begin{array}{c}95.0 \% \text { CI } \\
\text { Lower bound }\end{array}$} \\
\hline & & & & & & & & & \\
\hline \multicolumn{2}{|l|}{ Age } & -0.159 & 0.002 & -0.109 & 0.038 & -0.102 & -2.136 & 0.033 & -0.436 \\
\hline \multicolumn{2}{|c|}{ Civil status (single) } & -0.196 & 0.000 & -0.149 & 0.004 & -0.157 & -3.362 & 0.001 & -17.744 \\
\hline \multicolumn{2}{|c|}{ Nationality (Canadian) } & -0.070 & 0.048 & -0.099 & 0.041 & -0.081 & -1.767 & 0.078 & -14.975 \\
\hline \multicolumn{2}{|c|}{ Quality of life (SLDS score) } & 0.074 & 0.015 & 0.058 & 0.030 & 0.132 & 2.326 & 0.021 & 0.025 \\
\hline \multicolumn{2}{|c|}{ Type of housing (autonomous) } & & & 0.188 & 0.001 & 0.142 & 2.847 & 0.005 & 2.152 \\
\hline \multicolumn{2}{|c|}{ Social support (SPS score) } & & & 0.143 & 0.011 & 0.131 & 2.564 & 0.011 & 0.090 \\
\hline \multicolumn{2}{|c|}{ Number of diagnoses } & & & & & -0.134 & -2.901 & 0.004 & -5.888 \\
\hline \multicolumn{2}{|c|}{$\begin{array}{l}\text { Functional status in community } \\
\text { (MCAS score) }\end{array}$} & & & & & 0.092 & 1.982 & 0.048 & 0.002 \\
\hline \multicolumn{2}{|c|}{$\begin{array}{l}\text { Number of perceived needs } \\
\text { (MANQ) }\end{array}$} & & & & & 0.450 & 8.592 & 0.000 & 1.906 \\
\hline \multicolumn{2}{|l|}{$\begin{array}{l}\text { Total variance } \\
\text { explained: } \mathrm{R}^{2}\end{array}$} & \multicolumn{2}{|c|}{$14.3 \%$} & \multicolumn{2}{|c|}{$25.2 \%$} & \multicolumn{4}{|c|}{$30.5 \%$} \\
\hline \multirow{2}{*}{ Goodness-of-fit } & $\mathrm{F}$ & \multicolumn{2}{|c|}{7.770} & \multicolumn{2}{|c|}{9.402} & \multicolumn{4}{|c|}{16.712} \\
\hline & $\mathrm{P}$ & \multicolumn{2}{|c|}{$<0.001$} & \multicolumn{2}{|c|}{$<0.001$} & \multicolumn{4}{|c|}{$<0.001$} \\
\hline
\end{tabular}


Table 4. Variables independently associated with level of help received from services among patients with mental disorders: multiple linear regression analysis $(\mathrm{N}=352)$.

\begin{tabular}{|c|c|c|c|c|c|c|c|c|c|c|}
\hline & & \multicolumn{2}{|c|}{$\begin{array}{l}\text { Predisposing } \\
\text { factors }\end{array}$} & \multicolumn{2}{|c|}{ Enabling factors } & \multicolumn{5}{|c|}{ Need factors } \\
\hline & & \multirow{2}{*}{\multicolumn{2}{|c|}{$\mathbf{P}$}} & & \multirow[b]{2}{*}{$\mathbf{P}$} & \multirow[b]{2}{*}{$\begin{array}{c}\text { Standardized } \\
\beta\end{array}$} & \multirow[b]{2}{*}{$\mathbf{t}$} & \multirow[b]{2}{*}{$\mathbf{P}$} & \multicolumn{2}{|c|}{$95.0 \% \mathrm{CI}$} \\
\hline & & & & & & & & & $\begin{array}{l}\text { Lower } \\
\text { bound }\end{array}$ & $\begin{array}{l}\text { Upper } \\
\text { bound }\end{array}$ \\
\hline \multicolumn{2}{|c|}{ Quality of life (SLDS score) } & 0.074 & 0.016 & 0.005 & 0.019 & 0.289 & 5.772 & 0.000 & 0.220 & 0.447 \\
\hline \multicolumn{2}{|l|}{$\begin{array}{l}\text { Type of housing } \\
\text { (autonomous) }\end{array}$} & & & -0.218 & 0.000 & -0.230 & -4.891 & 0.000 & -14.935 & -6.368 \\
\hline \multicolumn{2}{|l|}{ Schizophrenia } & & & & & 0.110 & 2.421 & 0.016 & 0.966 & 9.334 \\
\hline \multicolumn{2}{|c|}{ Adjustment disorder } & & & & & 0.124 & 2.935 & 0.004 & 4.907 & 24.852 \\
\hline \multicolumn{2}{|c|}{$\begin{array}{l}\text { Number of perceived needs } \\
\text { (MANQ) }\end{array}$} & & & & & 0.641 & 13.292 & 0.000 & 2.844 & 3.832 \\
\hline \multicolumn{2}{|c|}{ Total variance explained: $\mathrm{R}^{2}$} & \multicolumn{2}{|c|}{$0.08 \%$} & \multicolumn{2}{|c|}{$0.21 \%$} & \multicolumn{5}{|c|}{$39.1 \%$} \\
\hline \multirow{2}{*}{ Goodness-of-fit } & $\mathrm{F}$ & \multicolumn{2}{|c|}{1.930} & \multicolumn{2}{|c|}{8.855} & \multicolumn{5}{|c|}{44.415} \\
\hline & $\mathrm{P}$ & \multicolumn{2}{|c|}{$<0.001$} & \multicolumn{2}{|c|}{$<0.001$} & \multicolumn{5}{|c|}{0.001} \\
\hline
\end{tabular}

lower prevalence of psychotic symptoms. Our sample also presented a higher proportion of physical health needs. According to Hansson et al. [14], women, older persons, out-patients and individuals without a diagnosis of psychosis have a higher risk of presenting a need in this domain. Intensity of need is particularly high with regards to intimate relationships and sexual expression, which is similar to what most previous studies have shown [15,16,37-39]. Lack of specialised services in these areas could explain the high level of need $[35,40]$. Users generally perceived medication as being the main cause of their sexual problems [39]. Moreover, caregivers were often unaware of their clients' needs regarding intimate relationships and sexual expression [12, 39,40]. Drugs, childcare, job integration and benefits are other areas where the level of need was particularly high. This is likely as a result of the difficulties in coordinating mental health services with other health or social services [18].

Like previous studies [4,10,12,15-17,19], our results show that the level of help from services is particularly high in health-related areas, such as psychotic symptoms, physical health, psychological distress and drugs. There are areas where clinical treatment and out-patient services were clearly identified [4]. Formal help was lower in social (company, intimate relationships, sexual expression), basic (accommodation, food, day-time activities) functioning (looking after the home, money, childcare, self-care, basic education) and service needs (transportation, benefits, information about illness and treatment, telephone). In such areas, relatives can act as adjuncts to existing services and supply additional help [16].

Areas where relatives provided the most help were the same as those described in previous studies [16]. In areas like childcare, looking after the home, basic education, food, company, intimate relationships, transportation and telephone, the level of help from relatives was higher or equal to help received from services. These areas traditionally fall within the purview of the family [7].

Finally, a high proportion of users' needs was not met or was insufficiently met by services or relatives. Mental health services are underused by individuals with mental disorders $[41,42]$ and, as a result, several needs are not adequately met.

Two variables were significantly associated with both formal and informal help: number of needs and quality of life. It makes sense that individuals with a greater number of perceived needs would be more likely to receive help from a greater variety of sources [9]. As concerns quality of life, a greater number of needs are associated with a favourable outcome according the literature [43]. It could indicate that consumers are more aware of their needs, that services perform better assessments or that there is closer consumer follow-up or greater service utilisation [44].

There is a difference between formal and informal help supplied according to the type of housing. Help from services is significantly more important in supported housing, while families provide most of the help to their relatives in autonomous housing. Individuals with poorer functional status must be placed in supported housing (foster homes, intermediary resources, temporary housing, supervised housing, etc.). This is the case of individuals affected by negative symptoms of schizophrenia [45]. It is logical to expect that those individuals would be more susceptible to having contacts with professional caregivers and receiving more help from services, for their health needs, but also in other areas (accommodation, food, day-time activities, etc.) 
usually provided by the family.

According to Andersen's Behavioural Model of Health Service Use [20], need factors are the most influential factors of health service utilisation. Help from services is significantly associated with two particular diagnoses: schizophrenia and adjustment disorder. As schizophrenia affects most of life's areas, it makes sense that individuals affected by this chronic mental disorder would receive more help from services [45]. Adjustment disorder is a prime cause of psychiatric consultation. According the literature, the incidence of this mental disorder in psychiatric consultation services for adults would be between $5 \%$ and $21 \%[46,47]$. Adjustment disorder is encountered commonly in primary care and usually followedup in liaison psychiatry [47,48]. It is important to consider that no users in our sample were affected exclusively by an adjustment disorder. This is a second diagnosis for some individuals affected by a severe mental disorder (schizophrenia, mood disorders, etc.).

Predisposing factors (age, civil status and nationality) are more often associated to help from relatives. The association between age and help from relatives can be explained by the fact that younger people are more likely to live with their parents and to have a larger social networks than older users [7]. In terms of marital status, living with a spouse is conducive to sharing, which helps in fulfilling basic needs and those of health and social nature. Individuals with SMD living in a conjugal relationship have a higher quality of life and are less likely to have suicidal ideation than single, divorced, widowed or estranged persons [49]. Finally, concerning nationality, in some cultures (e.g. Spain, India) families and friends represent the main source of help except in the areas where specialized services are required $[4,19]$.

There exists a logical association between quality of the social support and level of help received from relatives. We can also establish a link between help received from relatives, lower number of diagnoses and the ability to function better in the community, according to the MCAS. This shows that family and friends are better able to give help to individuals who are less problematic, more clinically stable and less susceptible to represent a burden for them [17].

Relatives are key caregivers who should be included in the planning of care for users suffering from SMD. Evidence-based practice such as psycho-educational intervention for families [50] and respite services to reduce the burden on families should be enhanced. These interventions could indirectly improve relatives' capacity to provide adequate help for their loved ones suffering from SMD.

\section{LIMITATIONS}

Our study includes certain notable limitations. First, information was lacking about family and social networks of our respondents. It is possible that some sociodemographic, economic or geographic variables (age of caregivers, familial income, employment, proximity, etc.) influence relatives' capacity to give help to individuals with SMD [51]. Secondly, while we had information about the number of relatives or professionals giving help and the frequency of their contacts or visits, we did not know the frequency and quality of relationships between families and mental health services. More effective collaboration with health services can influence informal help [51]. Families are often unsatisfied of the services offered to a relative suffering from a mental disorder [52]. In addition, they do not receive information and emotional support from professionals [53] or are excluded from decisions concerning treatment of hospital discharge planning [54]. There is also a severe lack of respite care for family caregivers [55].

\section{CONCLUSION}

Our study demonstrates that help overall is insufficient, both in quantity and intensity, to meet users' needs. Services are more helpful than relatives, but mostly for health domains. However, relatives can give substantial help to individuals who are clinically stable in domains such as childcare, food and looking after the home-without adding to much burden on family. These domains are often overlooked or neglected by mental health professionals. Formal and informal help are in fact complementary therefore; a greater collaboration between relatives and service providers could contribute to better meet the needs of individuals with SMD. Being aware of factors associated with help improves services' capacity to complete adequately with help from relatives and viceversa. Overall, our results reinforce the importance of consolidate strategies to reach patients and answer more broadly their needs, and this in a concerted common effort between services and family.

\section{ACKNOWLEDGEMENTS}

The study was funded by the Canadian Institute of Health Research (CIHR-MOP-84512). We would like to thank this grant agency and all the users who participated in the research.

\section{REFERENCES}

[1] Pitschel-Walz, G., Leutch, S., Bäuml, J., Kissling, W. and Engel, R.R. (2001) The effect of family interventions on relapse and rehospitalization in schizophrenia-A metaanalysis. Schizophrenia Bulletin, 27, 73-92. doi:10.1093/oxfordjournals.schbul.a006861

[2] Anthony, W.A., Cohen, M. and Farkas, M. (1990) Psychiatric rehabilitation. Boston University Centre for Psychiatric Rehabilitation, Boston. 
[3] Ward-Griffin, C., Scholfield, R., Vos, S. and CoatsworthPuspoky, R. (2005) Canadian families caring for members with mental illness: A vicious cycle. Journal of Family Nursing, 11, 140-161. doi: $10.1177 / 1074840705275464$

[4] Ochoa, S., Haro, J.M., Autonell, J., Pendàs, A., Teba, F., Màrquez, M. and the NEDES Group (2003) Met and unmet needs of schizophrenia patients in a Spanish sample. Schizophrenia Bulletin, 29, 201-210. doi:10.1093/oxfordjournals.schbul.a006998

[5] Lam, J.A. and Rosenheck, R. (1999) Social support and service use among homeless persons with serious mental illness. International Journal of Social Psychiatry, 45, 1328. doi:10.1177/002076409904500103

[6] Snowden, L.R. (1998) Racial differences in informal help seeking for mental health problems. Journal of Community Psychology, 26, 429-438.

doi:10.1002/(SICI)1520-6629(199809)26:5<429::AID-JC OP3>3.0.CO;2-M

[7] Horwitz, A.V. and Uttaro, T. (1998) Age and mental health services. Community Mental Health Journal, 34, 275-283. doi:10.1023/A:1018717808191

[8] Pescosolido, B.A., Wright, E.R., Alegria, M. and Vera, M. (1998) Social networks and patterns of use among the poor with mental health problems in Puerto Rico. Medical Care, 36, 1057-1072. doi:10.1097/00005650-199807000-00012

[9] Woodward, A.T., Taylor, R.J., Bullard, K.M., Neighbors, H.W., Chatters, L.M. and Jackson, J.S. (2008) Use of professional and informal support by African Americans and Caribbean blacks with mental disorders. Psychiatric Services, 59, 1292-1298. doi:10.1176/appi.ps.59.11.1292

[10] Cedereke, M. and Ojehagen, A. (2007) Formal and informal help during the year after a suicide attempt: A one year follow-up. International Journal of Social Psychiatry, 53, 419-429. doi:10.1177/0020764007078345

[11] Macpherson, R., Haynes, R., Summerfield, L., Foy, C. and Slade, M. (2003) From research to practice. A local mental health services needs assessment. Social Psychiatry and Psychiatric Epidemiology, 38, 276-281. doi:10.1007/s00127-003-0629-0

[12] Simons, L. and Petch, A. (2002) Needs assessment and discharge: A Scottish perspective. Journal of Psychiatric and Mental Health Nursing, 9, 435-445. doi:10.1046/j.1365-2850.2002.00506.x

[13] Schölzel-Dorenbos, C.J., Meeuwsen, E.J. and Olde-Rikkert, M.G. (2010) Integrating unmet needs into dementia health-related quality of life research and care: Introduction of the hierarchy model of needs in dementia. Aging \& Mental Health, 14, 113-119. doi:10.1080/13607860903046495

[14] Hansson, L., Björkman, T. and Svensson, B. (1995) The assessment of needs in psychiatric patients. Interrater reliability of the Swedish version of the Camberwell assessment of needs instrument and results from a crosssectional study. Acta Psychiatrica Scandinavica, 92, 285293. doi:10.1111/j.1600-0447.1995.tb09584.x

[15] Bengtsson-Tops, A. and Hansson, L. (1999) Clinical and social needs of schizophrenic outpatients living in the community: The relationship between needs and subjective quality of life. Social Psychiatry and Psychiatric Epidemiology, 34, 513-518. doi:10.1007/s001270050169

[16] Middleboe, T., Mackeprang, T., Hansson, L., Werdelin, G., Karlsson, H., Bjarnason, O., Bengtsson-Tops, A., Dybbro, J., Nilsson, L.L., Sandlund, M. and Sörgaard, K.W. (2001) The Nordic study on schizophrenic patients living in the community. Subjective needs and perceived help. European Psychiatry, 16, 207-214. doi:10.1016/S0924-9338(01)00566-1

[17] Fleury, M.J., Grenier, G., Caron, J. and Lesage, A. (2008) Patient's report of help provided by relatives and services to meet their needs. Community Mental Health Journal, 44, 271-281. doi:10.1007/s10597-008-9127-x

[18] Cummings, S.M. and Kropf, N.P. (2009) Formal and informal support for older adults with severe mental illness. Aging \& Mental Health, 13, 619-627. doi:10.1080/13607860902774451

[19] Kulhara, P., Avashthi, A., Grover, S., Sharan, P., Sharma, P., Malhotra, S. and Gill, S. (2010) Needs of Indian schizophrenia patients: An exploratory study from India. Social Psychiatry and Psychiatric Epidemiology, 45, 809818. doi:10.1007/s00127-009-0126-1

[20] Andersen, R.M. (1995) Revisiting the behavioral model and access to medical care: Does it matter? Journal of Health and Social Behavior, 36, 1-10. doi: $10.2307 / 2137284$

[21] Phelan, M., Slade, M., Thornicroft, G., Dunn, G., Holloway, F., Wykes, T., Strathdee, G., Loftus, L., McCrone, P. and Hayward, P. (1995) The Camberwell assessment of need: The validity and reliability of an instrument to assess the needs of people with severe mental illness. British Journal of Psychiatry, 167, 589-595. doi:10.1192/bjp.167.5.589

[22] Corbière, M., Zaniboni, S., Lecomte, T., Bond, G.R., Gilles, P.Y., Lesage, A. and Goldner, E. (2011) Job acquisition for people with severe mental illness enrolled in supported employment programs: A theoretically grounded empirical study. Journal of Occupational Rehabilitation, 21, 342-354. doi:10.1007/s10926-011-9315-3

[23] Schulze, B. and Angermeyer, M.C. (2003) Subjective experiences of stigma. A focus group study of schizophrenic patients, their relatives and mental health professionals. Social Science \& Medicine, 56, 299-312. doi:10.1016/S0277-9536(02)00028-X

[24] Stuart, H. (2003) Stigma and the daily news: Evaluation of a newspaper intervention. Canadian Journal of Psychiatry, 48, 651-656.

[25] Pruessner, M., Iyer, S.N., Faridi, K., Joober, R. and Malla, A.K. (2011) Stress and protective factors in individuals at ultra-high risk for psychosis, first episode psychosis and healthy controls. Schizophrenia Research, 129, 29-35. doi:10.1016/j.schres.2011.03.022

[26] Piat, M., Sabetti, J. and Bloom, D. (2010) The transformation of mental health services to a recovery-oriented system of care: Canadian decision maker perspectives. International Journal of Social Psychiatry, 56, 168-177. doi:10.1177/0020764008100801

[27] Accietto, C. (2003) La validation d'une version française 
du questionnaire A.U.D.I.T. Alcohol use identification test. Ph.D. Thesis, Geneva University, Geneva.

[28] Carey, K.B., Carey, M.P. and Chandra, P.S. (2003) Psychometric evaluation of the Alcohol Use Disorders Identification Test and Short Drug Abuse Screening Test with psychiatric patients in India. Journal of Clinical Psychiatry, 64, 767-774. doi:10.4088/JCP.v64n0705

[29] Caron, J. (1996) L'échelle de provisions sociales: Une validation québécoise. Santé mentale au Québec, 21, 158180. doi:10.7202/032403ar

[30] Caron, J., Mercier, C. and Tempier, R. (1997) Une validation québécoise du satisfaction with life Domains Scale. Santé mentale au Québec, 17, 195-218. doi:10.7202/032422ar

[31] Hendryx, M.S., Dyck, D.G., McBride, D. and Whitbeck, J. (2001) A test of the reliability and validity of the Multnomah Community Ability Scale. Community Mental Health Journal, 37, 157-168. doi:10.1023/A:1002713816110

[32] Fleury, M.J., Grenier, G., Bamvita, J.M. and Tremblay, J. (2013) Factors associated with needs of users with severe mental disorders. Psychiatric Quarterly.

[33] Babor, T.F., Higgins-Biddle, J.C., Saunders, J.B. and Monteiro, M. (2001) Audit. The Alcohol Use Disorders Identification Test guidelines for use in primary care. 2nd Edition, Department of Mental Health and Substance Dependence, World Health Organization, Geneva.

[34] Slade, M., Phelan, M. and Thornicroft, G. (1998) A comparison of needs assessed by staff and by an epidemiologically representative sample of patients with psychosis. Psychological Medicine, 28, 543-550. doi:10.1017/S0033291798006564

[35] Slade, M., Leese, M., Cahill, S., Thornicroft, G. and Kuipers, E. (2005) Patient-rated mental health needs and quality of life improvement. British Journal of Psychiatry, 187, 256-261. doi:10.1192/bjp.187.3.256

[36] Wennström, E., Sörbom, D. and Wiesel, F.A. (2004) Factor structure in the Camberwell Assessment of Need. British Journal of Psychiatry, 185, 505-510. doi:10.1192/bjp.185.6.505

[37] McCrone, P., Leese, M., Thornicroft, G., Schene, A., Knudsen, H.C., Vàzquez-Barquero, J.L., Tansella, M. and Becker, T. (2001) A comparison of needs of patients with schizophrenia in five European countries: The EPSILON study. Acta Psychiatrica Scandinavica, 103, 370-379. doi:10.1034/j.1600-0447.2001.00207.x

[38] Wiersma, D., van den Brink, R., Wolters, K., McCabe ,R., Bullenkamp, J., Hansson, L., Lauber, C., Martinez-Leal, R., Rössler, W., Salize, H., Björkman, T., Torres-Gonzales, F., Wright, D.J. and Priebe, S. (2009) Individual unmet needs for care: Are they sensitive as outcome criterion for the effectiveness of mental health services interventions? Social Psychiatry and Psychiatric Epidemiology, 44, 317324. doi:10.1007/s00127-008-0432-Z

[39] McCann, E. (2010) The sexual and relationship needs of people who experience psychosis: Quantitative findings of a UK study. Journal of Psychiatric and Mental Health Nursing, 17, 295-303.

doi:10.1111/j.1365-2850.2009.01522.x
[40] Slade, M. (1996) Assessing the needs of the severely mentally ill: Cultural and professional differences. International Journal of Social Psychiatry, 42, 1-9. doi: $10.1177 / 002076409604200101$

[41] Andrews, G., Issakidis, C. and Carter, G. (2001) Shortfall in mental health service utilisation. British Journal of Psychiatry, 179, 417-425. doi:10.1192/bjp.179.5.417

[42] Tempier, R., Meadows, G.N., Vasiliadis, H.M., Mosier, K.E., Lesage, A., Stiller, A., Graham, A. and Lepnurm, M. (2009) Mental disorders and mental health care in Canada and Australia: Comparative epidemiological findings. Social Psychiatry and Psychiatric Epidemiology, 44, 63-72. doi:10.1007/s00127-008-0409-y

[43] Leese, M., Johnson, S., Slade, M., Parkman, S., Kelly, F., Phelan, M. and Thornicroft, G. (1998) User perspective on needs and satisfaction with mental health services. PRiSM psychosis study. 8. British Journal of Psychiatry, 173, 409-415. doi:10.1192/bjp.173.5.409

[44] Fleury, M.J., Piat, M., Grenier, G., Bamvita, J.M., Boyer, R., Lesage, A. and Tremblay, J. (2010) Components associated with adequacy of help for consumers with severe mental disorders. Administration and Policy in Mental Health and Mental Health Services Research, 37, 497508. doi:10.1007/s10488-010-0292-1

[45] Song, L. and Singer, M. (2001) The social functioning of persons with chronic mental illness: An empirical typology of consumers and correlates of social functioning. International Journal of Social Psychiatry, 47, 36-51. doi: $10.1177 / 002070400104700104$

[46] Carta, M.G., Balestrieri, M., Murru, A. and Hardoy, M.C. (2009) Adjustment disorder: Epidemiology, diagnosis and treatment. Clinical Practice and Epidemiology in Mental Health, 5, 15. doi:10.1186/1745-0179-5-15

[47] Jones, R., Yates, W.R., Williams, S., Zhou, M. and Hardman, L. (1999) Outcome for adjustment disorder with depressed mood: Comparison with other mood disorders. Journal of Affective Disorders, 55, 55-61. doi:10.1016/S0165-0327(98)00202-X

[48] Casey, P. (2001) Adult adjustment disorder: A review of its current diagnostic status. Journal of Psychiatric Practice, 7, 32-40. doi:10.1097/00131746-200101000-00004

[49] Nyer, M., Kascow, J., Fellows, I., Lawrence, E.C., Golshan, S., Solorzano, E. and Zisook, S. (2010) The relationship of marital status and clinical characteristics in middle-aged and older patients with schizophrenia and depressive symptoms. Annals of Clinical Psychiatry, 22, 172-179.

[50] Drake, R.E., Goldman, H.H., Leff, H.S., Lehman, F., Dixon, L., Mueser, K.T. and Torrey, W.C. (2001) Implementing evidence-based practices in routine mental health service settings. Psychiatric Services, 52, 903-910. doi:10.1176/appi.ps.52.2.179

[51] Holmes, A.M. and Deb, P. (1998) Factors influencing informal care-giving. Journal of Mental Health Policy and Economics, 1, 77-87. doi:10.1002/(SICI)1099-176X(199807)1:2<77::AID-MH P10>3.0.CO;2-5

[52] Ruggeri, M., Dall'Agnola, C., Agostini, C. and Bisoffi, G. (1994) Acceptability, sensitivity and content validity of 
the VESC and VSSS in measuring expectations and satisfaction in psychiatric patient and their relatives. Social Psychiatry and Psychiatric Epidemiology, 29, 265-276. doi:10.1007/BF00802049

[53] Doornbos, M.M. (2002) Family caregivers and the mental health care system: Reality and dreams. Archives of Psychatric Nursing, 16, 39-46. doi:10.1053/apnu.2002.30541

[54] Perreault, M., Tardif, H., Provencher, H., Paquin, G., Des- marais, J. and Pawliuk, N. (2005) The role of relatives in discharge planning from psychiatric hospitals: The perspective of patients and their relatives. Psychiatric Quarterly, 76, 297-315. doi:10.1007/s11126-005-4964-z

[55] Jeon, Y.H., Brodaty, H. and Chesterson, J. (2005) Respite care for caregivers and people with severe mental illness: Literature review. Journal of Advanced Nursing, 49, $297-$ 306. doi:10.1111/j.1365-2648.2004.03287.x 